\title{
Longitudinal data assessment of global stability index in kale leaves
}

\author{
Alcinei Mistico Azevedo ${ }^{1 *}$, Valter Carvalho de Andrade Júnior², Carlos Enrrik Pedrosa ${ }^{3}$, Nermy Ribeiro Valadares², Marcos Aurélio Miranda \\ Ferreira ${ }^{2}$, Paulo Roberto Cecon ${ }^{1}$
}

${ }^{1}$ Federal University of Vicosa, Av. Peter Henry Rolfs, s/n 36570-000 - Viçosa, MG - Brazil.

${ }^{2}$ Federal University of the Jequitinhonha and Mucuri Valleys, Campus JK, Rod. MGT 367 - km 583, nº 5000 - 39100-000

- Diamantina, MG - Brazil.

${ }^{3}$ Federal University of Lavras, Campus Universitário, C.P.

3037 - 37200-000 - Lavras, MG - Brazil.

*Corresponding author <alcineimistico@hotmail.com>

Edited by: Antonio Costa de Oliveira

Received September 22, 2014

Accepted July 14, 2015
ABSTRACT: Kale plants are usually sold "in natura" in street markets and malls. Kale leaves can have their appearance compromised by dehydration and discoloration due to increased postharvest time exposure. We aimed to analyze the Global Stability Index (GSI) in kale accessions by means of repeated measurement analysis and curve grouping as a complementary form of superior sample identification with regard to post-harvest preservation. Thirty kale accessions were evaluated using a randomized block design with four blocks and five plants per plot. Two commercial leaves per plant were collected, and kept on workbenches in the shade at a temperature of $18 \pm 1^{\circ} \mathrm{C}$. Subsequently, the degrees of discoloration and dehydration, total chlorophyll content, and accumulated fresh mass loss were evaluated over a 15-day period. From these data, the GSI was calculated for each day of evaluation. In addition, using mixed models, thirteen co-variance structures were tested. For graphical analysis, thirteen linear and non-linear models were assessed followed by curve grouping using multivariate analysis. The GSI was efficient for differentiating accessions, which became an important tool in post-harvest studies. GSI values were not equally correlated, therefore the use of mixed models became an important approach. The unstructured matrix was the best fit to model the dependence of error. The Melow I model was the best fit for studying the GSI. The accessions UFVJM-10, UFLA-1, COM-1, UFVJM-32, COM-3, UFVJM-8, UFVJM-36 and UFVJM-24, belonging to 3 and 5 clusters, are recommended for crop cultivation and as parental material in breeding programs.

Keywords: Brassica oleracea var. acephala DC, post-harvest preservation, repeated measurements, multivariate statistics, curve grouping

\section{Introduction}

Several studies were conducted on the kale crop (Brassica oleracea var. acephala DC) which revealed its health benefits (Ayaz et al., 2008; Sousa et al., 2008; Lemos et al., 2011). The appearance of Kale leaves is compromised by dehydration and discoloration due to post-harvest time exposure. Thus, cultivation of varieties resistant to this early dehydration and discoloration is a desirable trait.

Vegetable dehydration over periods of storage is commonly evaluated by water loss measurement (Aguero et al., 2011) and a rating scale. However, discoloration can also be assessed by considering the chlorophyll content, which has also been efficiently evaluated, in some reports, by a rating scale (Agüero et al., 2008; Agüero et al., 2011; Martínez-Sánchez et al., 2011; Atkinson et al., 2013a; Atkinson et al., 2013b). When many characteristics are taken into account in a post-harvest study, it becomes difficult to make a decision. Achour (2006) proposed a method called the Global Stability Index (GSI) that allows for quantifying the stability of vegetable quality throughout a period, and aggregating information about a number of traits into a unique variable.

Along with the GSI approach, the use of mathematical modeling is an interesting tool for predicting shelf life (Ansorena et al., 2009). Being dimensionless, the index can also be used to compare the relative stability of two different products stored under the same conditions. This methodology showed itself to be effi- cient in the evaluation of beverages (Achour, 2006) and lettuce conservation (Ansorena et al., 2009; Ansorena et al., 2012) as a function of storage time.

Post-harvest study is generally performed in a series of successive evaluations for each experimental unit over the course of time. This kind of experiment has been improperly analyzed as split plots must be analyzed by a series of repeated measures. Another approach is graphical methods. With this technique, when a large number of treatments is performed, it becomes feasible to aggregate similar treatments with regard to the curves, i. e. treatments that present similar vectors to the estimates of adjusted model parameters. Thus, this study aimed to analyze the GSI of 30 kale accessions by means of repeated measure analysis with various co-variance structures, plotting curve grouping through multivariate analysis as a complement to the identification of superior vegetable material.

\section{Materials and Methods}

The experiment was carried out in the municipality of Diamantina, in the state of Minas Gerais, Brazil (18 $12^{\prime} 01^{\prime \prime}$ S; $43^{\circ} 34^{\prime} 20^{\prime \prime} \mathrm{W}, 1387$ m.a.s.l.). During the period of the experiment, the average temperature was $18.3^{\circ} \mathrm{C}$ and the relative air humidity was $80 \%$ with few oscillations.

Three commercial cultivars and twenty-seven kale accessions from the germplasm bank of UFVJM were used. The experimental design was a completely randomized block with four replications and five plants per plot. 
Nineteen accessions were obtained by collections in rural properties within the region of Diamantina-MG (UFVJM-2, UFVJM-3, UFVJM-4, UFVJM-5, UFVJM-7, UFVJM-8, UFVJM-9, UFVJM-10, UFVJM-13, UFVJM-19, UFVJM-21, UFVJM-22, UFVJM-24, UFVJM-26, UFVJM-27, UFVJM-30, UFVJM-32, UFVJM-34 and UFVJM-36) and eight accessions were donated by the Federal University of Lavras (UFLA-1, UFLA-3, UFLA-6, UFLA-8, UFLA-5, UFLA-10, UFLA-11 and UFLA-12). Three commercial cultivars were also studied (COM-1, COM-2 and COM-3).

On 28 Jul 2011, lateral sprouts were collected to form seedlings through herbaceous cutting propagation by collecting 3 - to $4-\mathrm{cm}$ high sprouts from mother-plants with two leaflets in the bottom third. After the sprout collections, the material was planted into 72-cell polystyrene trays filled with commercial substrate. Then, cuttings were transferred into a greenhouse in the Olericulture Sector of the UFVJM for 30 days in order to ensure optimal rooting. When the seedlings were ready, they were transplanted into $7.5 \mathrm{~kg}$ vessels filled with soil:manure in a 3:1 ratio. The vessels were kept under greenhouse conditions for a period of 30 days in order to ensure a high seedling survival rate

On 28 Sept 2011, vases were taken into the field where they remained until data collection for agricultural evaluation. Soil and top dressing fertilizations were carried out in accordance with crop recommendations; aphid and caterpillar control were manually administered on alternating days. In addition, old leaves and sprouts were removed weekly to allow for optimum plant development.

On 2 Jan 2012, two commercial leaves were collected from each plant (with absence of defects and leaf limb more than 20-cm long). These leaf samples were left on workbenches in the shade at $18 \pm 1{ }^{\circ} \mathrm{C}$. The valuations were performed at 0 (collection time), 1, 2, 3, 4, $5,7,9,11,13$ and 15 days after collection. The degrees of discoloration and dehydration, total chlorophyll content and accumulated loss of fresh mass were analyzed. Five previously trained individuals made evaluations according to a rating scale and degrees of discoloration and dehydration were assessed by visual examination. To define the degree of discoloration, the following rating scale was used: 1 (absence of discoloration), 2 (presence of low discoloration), 3 (moderate discoloration), 4 (moderate to severe discoloration) and 5 (severe discoloration). To define the degree of dehydration, the following rating scale was used: 1 (dehydration non-apparent), 2 (low dehydration), 3 (moderate dehydration), 4 (moderate to severe dehydration) and 5 (severe dehydration). Total chlorophyll was evaluated using a portable chlorophyll meter, taking three readings per leaf for each evaluation event. Accumulated fresh mass loss (FML) was obtained by the following equation: $F M L_{i}(\%)=\left(P_{0}-P_{i}\right) / P_{0}^{*} 100$, where $F M L_{i}$ is the accumulated fresh mass loss at $i$ time, $P_{0}$ is the weight of the kale head at harvest time and $P_{i}$ is the weight of the head at $i$ time.

Statistical analysis was carried out on a plot by plot basis, taking into account the mean of observed values for leaf evaluation (five plants per plot and two leaves per plant). For the best result in terms of viewing and interpretation, the Global Stability Index (GSI) was used as recommended by Achour (2006). For this index, the variation terms $\left(V_{i j}^{\prime}\right.$ s) were initially calculated as follows: $V_{i j}=\left(c_{i j}-c_{i 0}\right) /\left(L_{i}-c_{i 0}\right)$, where $C_{i j}$ is the measured value for the $i$ trait at $j$ time; $C_{i 0}$ is the initial value of the $i$ criterion at the moment of the first evaluation (time $=0$ ); $L_{i}$ is the threshold value of the $i$ trait, as established by the user. The value of $L_{i^{\prime}}$ which is used for all treatments, was such that the highest value for $V_{i j}$ may be equal to 1 , and values should increase in line with prolongations in storage time.

From the value of $V_{i j}$ it is possible to calculate the GSI for any $j$ time by using the expression: $\mathrm{GSI}_{j}=1-$ $\sum^{n}{ }_{i=1} \propto_{i}{ }^{*} V_{i j j^{\prime}}$ where $j$ is the $j$-th unit of time, $\sum^{\mathrm{n}}{ }_{\mathrm{i}=1}$ is the addition of $i=1$ up to $n$, in which $n$ is the total number of traits evaluated; $V_{i j}$ is the variation term of the $i$ criterion at $j$ time; and $\propto_{i}$ is the weight from the $i$ criterion, as established by the user. In this research study, in order to reach the same weight for each one of the four traits, $\propto_{i}$ $=0.25$ was adopted. Thus, as the values of $V_{i j}$ vary from 0 to 1 and the sum of the $\propto_{i}$ must be 1 , GSI also will also vary between 0 and 1 .

The mathematical model for the analysis of repeated measures of the GSI is given by: $y_{i j k^{\prime}}=\mu+$ $t_{i}+a_{j}+t a_{i j}+b_{k}+\varepsilon_{i j k}$, where $y_{i j k}=$ GSI value at the $j$ evaluation, in $k$ block and $i$ treatment; $\mu=$ global mean; $t_{i}=$ fixed effect of $i$ genotype; $a_{j}=$ fixed effect of $j$ evaluation; $(t a)_{i j}=$ fixed effect of the interaction between genotype and evaluation; $b_{k}=$ random effect of $k$ block; $\varepsilon_{i j k}=$ random error, $\varepsilon_{i j k} \sim N(0, V)$, in which, $V$ is the covariance matrix used to model error dependence that is associated with the GSI at $j$ evaluation, $k$ block, and $i$ genotype. It was assumed that error dependence occurs between $j^{\text {th }}$ and $j^{\prime}$ th $\left(j^{\text {th }} \neq j^{\text {th }}\right)$ in the evaluation of an identical experimental unit, in an identical block and, consequently, co-variance matrices feature in Figure 1.

The model was adjusted to the data by the maximum likehood estimate, using the PROC MIXED software (Statistical Analysis System, version 9.2), in which 13 co-variance matrices were tested. To identify the best matrix, the Akaike Information Criterion (AIC) and the Bayesian Information Criterion (BIC) were used. When fixing the time effect, mean values of the GSI of accessions were compared for each evaluation using the ScottKnott test $(p<0.05)$. This test was performed considering changes in adjusted co-variance structure by PROC MIXED, similarly to Cecon et al. (2008).

To describe the behavior of the GSI as a function of evaluation time, a statistical method similar to that described by Cecon et al. (2008) was adopted. In addition to the polynomial models of first degree, second degree and exponential, more complex models were also tested such as the Schnute, Mitscherlich, Richards, Gompertz, Logistics, Meloun I, von Bertalanffy and Michaelis-Menten. These models were adjusted for each replication by cultivar using the PROC MODEL from SAS ${ }^{\circledast}$ software (Statistical Analysis System, version 9.2). Afterwards, 


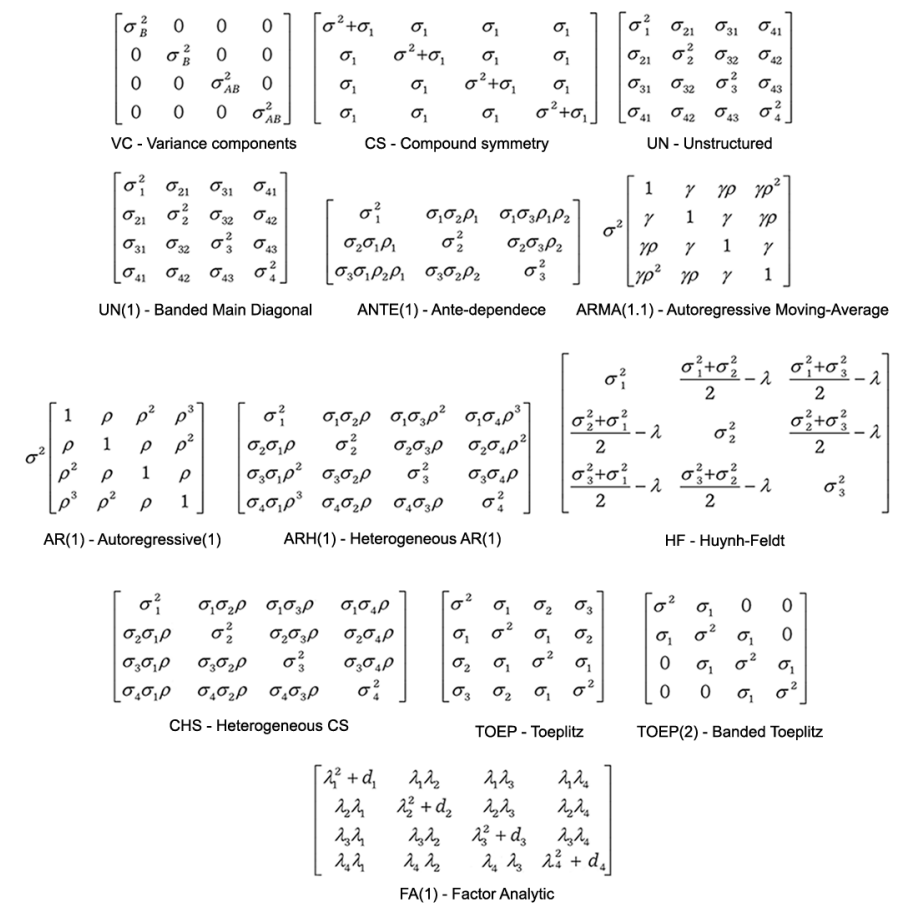

Figure 1 - Variances and co-variance structures used to model error dependence. Source: http://support.sas.com/

a multivariate variance analysis was carried out using a PROC GLM (Statistical Analysis System, version 9.2) with MANOVA option, in order to evaluate the accession effect on the estimates of model coefficients. Adjusted means were extracted from coefficients by least square (LSMEANS) and were subjected to clustering analysis in a PROC CLUSTER (Statistical Analysis System, version 9.2) by the centroid method.

In order to identify an optimal number of clusters, root mean squared standard deviation values (RMSSTD) were used. To view the dendrogram and check cultivars that belonged to different groups obtained by statistical discrimination, a PROC TREE (Statistical Analysis System, version 9.2) was used.

\section{Results and Discussion}

Verification of variance and co-variance matrix adjustments, by the Akaike Information Criterion (AIC) and the Bayesian Information Criterion (BIC) are shown in Table 1. The variance component structure (VC) presented the worst adjustment due to higher values for AIC and $\mathrm{BIC}$, and in this structure, zero co-variance among successive evaluations were admitted. This behavior is not expected for similar experiments, once using repeated measurements are taken, the responses of different evaluation times in the same plot, are not equally correlated (Araújo et al., 2009) as can be observed in Table 2. For this reason, a good adjustment for the composed symmetrical structure (CS) was not obtained and constant variances and co-variance are assumed.
Table 1 - Evaluators of adjustment quality of co-variance structures used for modeling the dependence of residuals.

\begin{tabular}{lcc}
\hline Structures & AIC & BIC \\
\hline Variance components & 2744.0 & 2746.8 \\
Compound symmetry & 2144.4 & 2150.0 \\
Compound heterogeneous symmetry & 1948.2 & 1978.8 \\
Unstructured & 1303.3 & 1402.4 \\
Unstructured banded main diagonal & 2607.7 & 2635.5 \\
Autoregressive & 1692.3 & 1697.9 \\
Autoregressive heterogeneous & 1473.3 & 1504.0 \\
Autoregressive moving average & 1675.3 & 1683.7 \\
Huynh-Feldt & 1905.4 & 1936.1 \\
Toeplitz & 1665.8 & 1693.7 \\
Banded Toeplitz & 2093.7 & 2099.3 \\
Factor Analytic & 1861.0 & 1916.8 \\
Ante-dependence & 1349.5 & 1456.6 \\
\hline Evaluators: Akaike Information Criterion (AIC) & and Bayesian & Information \\
Criterion (BIC). & &
\end{tabular}

According to García et al. (2010) if the sphericity condition is incorrectly met, which is equivalent to variance homogeneity in ANOVA analysis, apparent significance of difference between treatment means will be coarsely extrapolated and the sensitivity of interaction tests will be seriously reduced. An alternative to test matrix sphericity is to obtain an unstructured matrix (UN) and test it with the Huynh-Feldt matrix (H-F). Thus, using values of -2 Res Log Likelihood, freedom degrees of UN structure (1193.3 and 54), and of H-F (1883.4 and $10)$, the value of $X^{2}=|1193.3-1883.4|=690.1$ with 44 de- 
grees of freedom (54-10) was obtained, leading to a $p$-value lower than 0.001, indicating non-sphericity.

The unstructured matrix (UN) was the one that presented the best adjustment, with the lowest AIC and BIC values. According to Barnett et al. (2010) this co-variance matrix assumes that no two pairs of observations are equally correlated, and that there is no 'structure' between neighboring values in the matrix. Additionally,

Table 2 - Pearson correlation of Global Stability Index (GSI) values obtained in kale accessions at different storage points.

Times Day 2 Day 3 Day 4 Day 5 Day 7 Day 9 Day 11Day 13Day 15 \begin{tabular}{llllllllll}
\hline Day 1 & 0.977 & 0.878 & 0.802 & 0.712 & 0.560 & 0.541 & 0.586 & 0.603 & 0.664
\end{tabular} $\begin{array}{llllllllll}\text { Day } 2 & & 0.926 & 0.864 & 0.786 & 0.628 & 0.598 & 0.639 & 0.626 & 0.684\end{array}$ $\begin{array}{lllllllll}\text { Day } 3 \quad 0.970 & 0.915 & 0.754 & 0.712 & 0.727 & 0.679 & 0.716\end{array}$ $\begin{array}{lllllll}\text { Day } 4 & 0.947 & 0.816 & 0.766 & 0.768 & 0.673 & 0.701\end{array}$ $\begin{array}{lllllll}\text { Day } 5 & 0.943 & 0.910 & 0.878 & 0.783 & 0.795\end{array}$ $\begin{array}{llllll}\text { Day } 7 & 0.986 & 0.933 & 0.825 & 0.821\end{array}$ Day 9 $0.935 \quad 0.854 \quad 0.854$

Day 11 0.9340 .922

Day 13 0.981 it also allows for different variance terms along the diagonal of the matrix. From variance estimates for each evaluation in UN structure, a post-analysis of the interaction was carried out (evaluation date $\mathrm{x}$ accession) by using the Scott-Knott test for the grouping of means (Table 3). A procedure similar to this was implemented by Cecon et al. (2008), when assessing the productivity of 50 clonal varieties of coffee over five harvests.

The GSI behavior was described with respect to evaluation time by means of the graphical method. For this purpose, adjustments of different linear and non-linear models are displayed in Table 4. A good fit for the Brody model with the lowest AIC (26.238) was found, with the highest $\mathrm{R}^{2}$ value $(0.985)$ and $99 \%$ of convergence; however, The best model was considerd to be the Melow $\mathrm{I}\left(\mathrm{yi}=\beta_{1}-\beta_{2^{\mathrm{e}}}\left(-\beta_{3} \mathrm{x}_{\mathrm{i}}\right)+\varepsilon_{\mathrm{i}}\right)$, since in this model there was 100 $\%$ convergence with values around 26.285 for AIC and 0.984 for $\mathrm{R}^{2}$.

According to Souza et al. (2013), the coefficients adjusted by the Melow I model garner greater importance when the biological significance is taken into account, in which, $\beta_{1}$ reflects the individual final performance, and $\beta_{3}$ the progress rate of curves. These coefficients were used

Table 3 - Grouping of mean for the global stability index (GSI) of leaves kale evaluated at different storage points (Days).

\begin{tabular}{|c|c|c|c|c|c|c|c|c|c|c|}
\hline Genotypes & Day 1 & Day 2 & Day 3 & Day 4 & Day 5 & Day 7 & Day 9 & Day 11 & Day 13 & Day 15 \\
\hline UFVJM-2 & $0.153 \mathrm{~b}$ & $0.247 b$ & $0.345 \mathrm{~b}$ & $0.441 \mathrm{~b}$ & $0.495 b$ & $0.605 a$ & $0.647 a$ & $0.702 \mathrm{c}$ & $0.745 \mathrm{c}$ & $0.771 \mathrm{c}$ \\
\hline UFVJM-3 & $0.167 \mathrm{~b}$ & $0.275 a$ & $0.326 \mathrm{~b}$ & $0.421 \mathrm{~b}$ & $0.503 b$ & $0.648 a$ & $0.685 a$ & $0.755 b$ & $0.804 \mathrm{~b}$ & $0.822 b$ \\
\hline UFVJM-4 & $0.163 \mathrm{~b}$ & $0.267 \mathrm{~b}$ & $0.371 \mathrm{~b}$ & $0.473 \mathrm{a}$ & $0.520 \mathrm{a}$ & $0.623 a$ & $0.654 \mathrm{a}$ & $0.727 b$ & $0.770 \mathrm{~b}$ & $0.793 b$ \\
\hline UFVJM-5 & $0.197 \mathrm{~b}$ & $0.337 \mathrm{a}$ & $0.476 a$ & $0.545 \mathrm{a}$ & $0.622 \mathrm{a}$ & $0.699 a$ & $0.719 a$ & $0.770 \mathrm{~b}$ & $0.798 b$ & $0.830 \mathrm{~b}$ \\
\hline UFVJM-7 & $0.132 b$ & $0.199 \mathrm{~b}$ & $0.272 b$ & $0.349 \mathrm{~b}$ & $0.453 b$ & $0.608 a$ & $0.660 \mathrm{a}$ & $0.663 \mathrm{c}$ & $0.709 c$ & $0.747 \mathrm{c}$ \\
\hline UFVJM-36 & $0.144 \mathrm{~b}$ & $0.220 \mathrm{~b}$ & $0.296 \mathrm{~b}$ & $0.379 \mathrm{~b}$ & $0.421 \mathrm{~b}$ & $0.535 b$ & $0.576 \mathrm{~b}$ & $0.681 \mathrm{c}$ & $0.719 c$ & $0.748 c$ \\
\hline UFVJM-9 & $0.186 a$ & $0.315 \mathrm{a}$ & $0.445 a$ & $0.532 \mathrm{a}$ & $0.571 \mathrm{a}$ & $0.630 \mathrm{a}$ & $0.668 \mathrm{a}$ & $0.740 \mathrm{~b}$ & $0.795 \mathrm{~b}$ & $0.815 b$ \\
\hline UFVJM-10 & $0.149 b$ & $0.227 \mathrm{~b}$ & $0.306 \mathrm{~b}$ & $0.384 \mathrm{~b}$ & $0.417 \mathrm{~b}$ & $0.526 \mathrm{~b}$ & $0.562 \mathrm{~b}$ & $0.634 \mathrm{c}$ & $0.692 \mathrm{c}$ & $0.715 c$ \\
\hline UFVJM-13 & $0.165 \mathrm{~b}$ & $0.272 \mathrm{a}$ & $0.369 \mathrm{~b}$ & $0.462 \mathrm{a}$ & $0.496 \mathrm{~b}$ & $0.586 \mathrm{~b}$ & $0.614 b$ & $0.682 \mathrm{c}$ & $0.727 c$ & $0.750 \mathrm{c}$ \\
\hline UFVJM-19 & $0.152 b$ & $0.238 b$ & $0.315 b$ & $0.393 \mathrm{~b}$ & $0.465 \mathrm{~b}$ & $0.581 \mathrm{~b}$ & $0.622 b$ & $0.681 \mathrm{c}$ & $0.721 \mathrm{c}$ & $0.736 \mathrm{c}$ \\
\hline UFVJM-21 & $0.161 \mathrm{~b}$ & $0.247 \mathrm{~b}$ & $0.339 \mathrm{~b}$ & $0.417 \mathrm{~b}$ & $0.457 \mathrm{~b}$ & $0.558 \mathrm{~b}$ & $0.591 \mathrm{~b}$ & $0.709 \mathrm{~b}$ & $0.784 \mathrm{~b}$ & $0.804 \mathrm{~b}$ \\
\hline UFVJM-22 & $0.171 \mathrm{a}$ & $0.281 \mathrm{a}$ & $0.409 a$ & $0.513 \mathrm{a}$ & $0.561 \mathrm{a}$ & $0.652 \mathrm{a}$ & $0.681 \mathrm{a}$ & $0.733 b$ & $0.769 \mathrm{~b}$ & $0.807 \mathrm{~b}$ \\
\hline UFVJM-24 & $0.160 \mathrm{~b}$ & $0.255 b$ & $0.321 \mathrm{~b}$ & $0.360 \mathrm{~b}$ & $0.415 b$ & $0.506 \mathrm{~b}$ & $0.555 \mathrm{~b}$ & $0.652 c$ & $0.735 c$ & $0.769 c$ \\
\hline UFVJM-26 & $0.170 \mathrm{~b}$ & $0.278 a$ & $0.399 a$ & $0.504 \mathrm{a}$ & $0.576 a$ & $0.665 a$ & $0.693 a$ & $0.738 b$ & $0.778 b$ & $0.795 \mathrm{~b}$ \\
\hline UFVJM-27 & $0.177 \mathrm{a}$ & $0.296 a$ & $0.397 a$ & $0.492 \mathrm{a}$ & $0.542 \mathrm{a}$ & $0.655 a$ & $0.692 \mathrm{a}$ & $0.752 \mathrm{~b}$ & $0.804 \mathrm{~b}$ & $0.843 b$ \\
\hline UFVJM-30 & $0.153 b$ & $0.236 \mathrm{~b}$ & $0.328 \mathrm{~b}$ & $0.397 \mathrm{~b}$ & $0.470 \mathrm{~b}$ & $0.576 \mathrm{~b}$ & $0.607 \mathrm{~b}$ & $0.658 \mathrm{c}$ & $0.750 \mathrm{c}$ & $0.763 c$ \\
\hline UFVJM-32 & $0.138 b$ & $0.203 \mathrm{~b}$ & $0.278 b$ & $0.358 \mathrm{~b}$ & $0.437 \mathrm{~b}$ & $0.569 \mathrm{~b}$ & $0.615 b$ & $0.686 c$ & $0.717 \mathrm{c}$ & $0.729 c$ \\
\hline UFVJM-34 & $0.158 \mathrm{~b}$ & $0.256 b$ & $0.385 a$ & $0.486 \mathrm{a}$ & $0.561 \mathrm{a}$ & $0.664 \mathrm{a}$ & $0.696 a$ & $0.747 \mathrm{~b}$ & $0.777 \mathrm{~b}$ & $0.798 \mathrm{~b}$ \\
\hline UFVJM-8 & $0.163 b$ & $0.254 b$ & $0.339 \mathrm{~b}$ & $0.427 b$ & $0.470 \mathrm{~b}$ & $0.571 b$ & $0.616 b$ & $0.693 c$ & $0.734 \mathrm{c}$ & $0.770 \mathrm{c}$ \\
\hline COM-1 & $0.156 \mathrm{~b}$ & $0.248 \mathrm{~b}$ & $0.322 \mathrm{~b}$ & $0.390 \mathrm{~b}$ & $0.427 \mathrm{~b}$ & $0.510 \mathrm{~b}$ & $0.547 \mathrm{~b}$ & $0.619 c$ & $0.692 \mathrm{c}$ & $0.717 c$ \\
\hline COM-2 & $0.202 a$ & $0.333 a$ & $0.465 a$ & $0.580 \mathrm{a}$ & $0.654 \mathrm{a}$ & $0.771 \mathrm{a}$ & $0.815 a$ & $0.854 \mathrm{a}$ & $0.902 \mathrm{a}$ & $0.927 \mathrm{a}$ \\
\hline COM-3 & $0.150 \mathrm{~b}$ & $0.237 \mathrm{~b}$ & $0.335 b$ & $0.414 \mathrm{~b}$ & $0.459 \mathrm{~b}$ & $0.552 \mathrm{~b}$ & $0.601 \mathrm{~b}$ & $0.660 \mathrm{c}$ & $0.727 c$ & $0.762 \mathrm{c}$ \\
\hline UFLA-1 & $0.153 b$ & $0.249 b$ & $0.316 \mathrm{~b}$ & $0.390 \mathrm{~b}$ & $0.426 b$ & $0.531 \mathrm{~b}$ & $0.567 \mathrm{~b}$ & $0.653 c$ & $0.697 \mathrm{c}$ & $0.714 \mathrm{c}$ \\
\hline UFLA-3 & $0.148 b$ & $0.230 \mathrm{~b}$ & $0.334 \mathrm{~b}$ & $0.434 \mathrm{~b}$ & $0.469 \mathrm{~b}$ & $0.597 b$ & $0.614 \mathrm{~b}$ & $0.675 \mathrm{c}$ & $0.699 \mathrm{c}$ & $0.715 \mathrm{c}$ \\
\hline UFLA-6 & $0.165 \mathrm{~b}$ & $0.263 b$ & $0.339 \mathrm{~b}$ & $0.392 \mathrm{~b}$ & $0.484 \mathrm{~b}$ & $0.625 a$ & $0.672 \mathrm{a}$ & $0.757 \mathrm{~b}$ & $0.818 \mathrm{~b}$ & $0.844 b$ \\
\hline UFLA-8 & $0.183 a$ & $0.311 \mathrm{a}$ & $0.410 a$ & $0.498 a$ & $0.541 \mathrm{a}$ & $0.624 a$ & $0.666 \mathrm{a}$ & $0.715 b$ & $0.772 \mathrm{~b}$ & $0.798 b$ \\
\hline UFLA-5 & $0.190 \mathrm{a}$ & $0.288 a$ & $0.347 \mathrm{~b}$ & $0.406 \mathrm{~b}$ & $0.431 \mathrm{~b}$ & $0.536 \mathrm{~b}$ & $0.581 \mathrm{~b}$ & $0.642 \mathrm{c}$ & $0.712 \mathrm{c}$ & $0.747 \mathrm{c}$ \\
\hline UFLA-10 & $0.177 \mathrm{a}$ & $0.277 \mathrm{a}$ & $0.350 \mathrm{~b}$ & $0.417 \mathrm{~b}$ & $0.437 \mathrm{~b}$ & $0.526 \mathrm{~b}$ & $0.581 \mathrm{~b}$ & $0.646 c$ & $0.711 \mathrm{c}$ & $0.743 c$ \\
\hline UFLA-11 & $0.201 \mathrm{a}$ & $0.345 a$ & $0.439 a$ & $0.545 a$ & $0.585 a$ & $0.655 a$ & $0.675 a$ & $0.736 \mathrm{~b}$ & $0.756 \mathrm{c}$ & $0.810 \mathrm{~b}$ \\
\hline UFLA-12 & $0.177 \mathrm{a}$ & $0.297 \mathrm{a}$ & $0.399 \mathrm{a}$ & $0.495 \mathrm{a}$ & $0.543 \mathrm{a}$ & $0.636 a$ & $0.646 \mathrm{a}$ & $0.724 b$ & $0.746 \mathrm{c}$ & $0.771 \mathrm{c}$ \\
\hline
\end{tabular}

Means followed by same letter in the column do not differ from each other by the Scott-Knott (1974) test at $5 \%$ probability. 
for multivariate variance analysis, when a significant effect (p small or equal to 0.01) of accessions was detected in vectors of the coefficients studied by Wilks' lambda, Pillai's trace, Hotelling-Lawley and Roy's root tests. This indicates the need for more than one curve to explain the progress of GSI. Cecon et al. (2008) found similar results that corroborate the present ones. Therefore, fitted means were justified by the minimum squares of GSI as a function of accessions for grouping analysis by the centroid method.

The ideal number of clusters is presented in Figure 2, which is based on root-mean-square standard deviation (RMSSTD). The RMSSTD measures the homogeneity of the clusters formed (Liu et al., 2013) and enables identification of an optimal number of clusters by means of the maximum curvature method (Cecon et al, 2008). The use of this method is advantageous, since it allows for non-subjectivity of the stipulated number of groups in the dendrogram (Liu et al., 2013), showing feasibility for the formation of eight clusters (Figure 3). With the GSI means of each evaluation in function of the accessions that compose each cluster, eight curves were plotted and displayed in Figure 4. Using the same technique, Cecon et al. (2008) explained the behavior of 50 coffee accessions with 10 curves in respect of crop yield.

With respect to the GSI, higher values are undesirable since they indicate lesser stability throughout the post-harvest period. In this sense, COM-2 presented worse results, the group of accessions having the highest GSI for all evaluation periods (Table 3). Multivariate analysis showed that cluster 7 (Figure 3) was composed of this accession alone. Verification of the same undesired results of this accession are also $\mathrm{v}$ shown in Figure 4, in which the curve shows higher values for the GSI during storage.

Clusters 1 and 6 composed of UFVJM-5, UFVJM-22, UFVJM-26, UFLA-11, UFVJM-9, UFLA-12, UFVJM-34 and UFLA-6 accessions (Figure 3) have also not presented

Table 4 - Evaluators of adjustment quality in models used to describe the Global Stability Index (GSI) in kale leaves submitted in storage under room temperature.

\begin{tabular}{lccrr}
\hline Models & $\mathrm{R}^{2}$ & $\mathrm{R}_{\text {Ajst }}^{2}$ & \multicolumn{1}{c}{ AlC } & Conv. (\%) \\
\hline Schnute & 0.866 & 0.828 & 52.212 & 100.000 \\
Mitscherlich & 0.987 & 0.984 & 26.240 & 99.167 \\
Richards & 0.986 & 0.982 & 28.326 & 100.000 \\
Gompertz & 0.986 & 0.982 & 28.326 & 100.000 \\
Logistico & 0.980 & 0.974 & 32.489 & 100.000 \\
Meloun I & 0.988 & 0.984 & 26.285 & 100.000 \\
Meloun II & 0.988 & 0.984 & 26.373 & 95.833 \\
Brody & 0.988 & 0.985 & 26.238 & 99.167 \\
von Bertalanffy & 0.987 & 0.982 & 27.131 & 100.000 \\
Michaelis-Menten & 0.982 & 0.980 & 28.356 & 100.000 \\
Exponential & 0.822 & 0.800 & 53.731 & 100.000 \\
Polynomial models of $1^{\circ}$ degree & 0.899 & 0.886 & 46.881 & 100.000 \\
Polynomial models of $2^{\circ}$ degree & 0.978 & 0.972 & 31.791 & 100.000 \\
\hline Evaltor: R $(c 0$.
\end{tabular}

Evaluators: $\mathrm{R}^{2}$ (coefficient of determination), $\mathrm{R}_{\text {Aiss }}^{2}$ (adjusted coefficient of determination), AIC (Akaike Information Criterion), Conv.(percentage of convergence). good results in terms of the GSI (Figure 4). All these accessions were among the ones which presented higher GSI values, during the first 9 days of evaluation (Table 3). The best GSI results were found in clusters 3 and 5, when curves are close to the X-axis (Figure 4); these clusters were composed of the following accessions UFVJM-7,

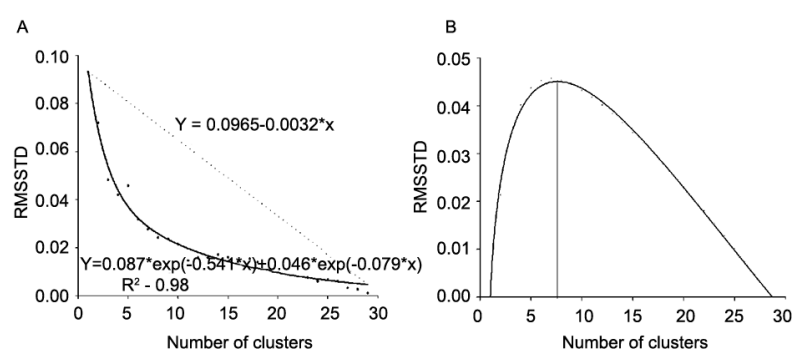

Figure 2 - Statistical behavior of root-mean-square standard deviation (RMSTSD), and distance between the straight line and the estimated curve (RMSTSD) for verification of optimal number of clusters by maximum curve method.

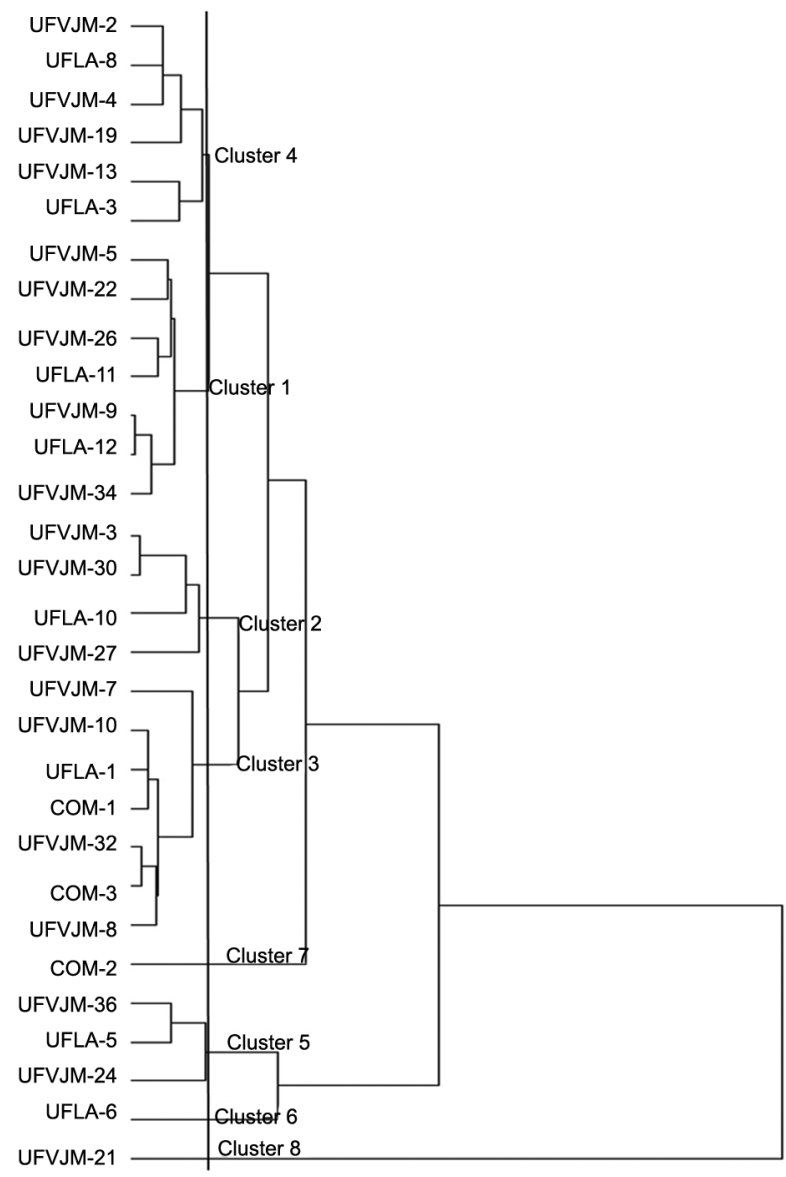

Figure 3 - Dendrogram by the centroid method for classification of genotypes considering the estimates of $\beta_{1}$ and $\beta_{3}$ coefficients obtained by the Melow I model for the Global Stability Index (GSI) in kale leaves as a function of storage time. 


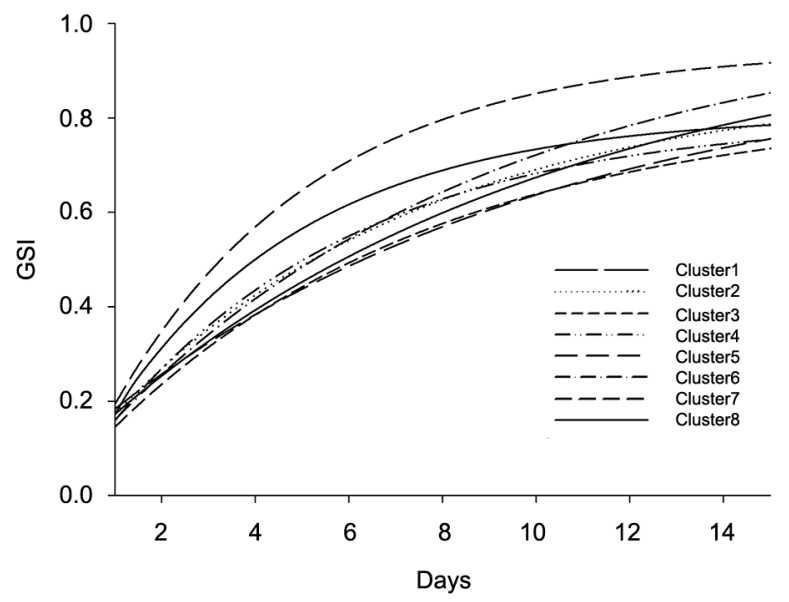

Figure 4 - Curves of global stability index (GSI) behavior for kale leaves in function of storage time (days) for each cluster formed by multivariate analysis.

UFVJM-10, UFLA-1， COM-1， UFVJM-32， COM-3， UFVJM-8, UFVJM-36, UFLA-5 and UFVJM-24 (Figure 3). Except for UFVJM-7 and UFLA-5 these accessions have remained in the group of lower GSI values for all evaluation periods (Table 3). Thus, these accessions are recommended for crop cultivation and as parental material in breeding programs.

\section{Conclusions}

The accessions UFVJM-10, UFLA-1, COM1, UFVJM-32, COM-3, UFVJM-8, UFVJM-36 and UFVJM-24, belonging to clusters 3 and 5, are recommended for crop cultivation and as parental material in breeding programs.

\section{Acknowledgements}

The authors thank Brazilian National Council for Scientific and Technological Development (CNPq), Coordination for the Improvement of Higher Level Personnel (CAPES) and Minas Gerais State Foundation for Research Support (FAPEMIG) for providing scholarships and resources to develop this study.

\section{References}

Achour, M. 2006. A new method to assess the quality degradation of food products during storage. Journal of Food Engineering 75: 60-564.

Agüero, M.V.; Barg, M.V.; Yommi, A.; Camelo, A.; Roura, S.I. 2008. Postharvest changes in water status and chlorophyll content of lettuce (Lactuca sativa L.) and their relationship with overall visual quality. Journal of Food Science 73: 47-55.

Agüero, M.V.; Ponce, A.G.; Moreira, M.R.; Roura, S.I. 2011. Lettuce quality loss under conditions that favor the wilting phenomenon. Postharvest Biology and Technology 59: 124-131.
Ansorena, M.R.; Goñi, M.G.; Aguëro, M.V.; Goni, M.G.; Roura, S.I.; Ponce, A.; Moreira, M R.; Di Scala, K.C. 2012. Assessment of lettuce quality during storage at low relative humidity using Global Stability Index methodology. Ciência e Tecnologia de Alimentos 32: 366-373.

Ansorena, M.R.; Goñi, M.G.; Aguëro, M.V.; Roura, S.I.; Di Scala, K.C. 2009. Application of the general stability index to assess the quality of butter lettuce during postharvest storage by a multiquality indices analysis. Journal of Food Engineering 92: 317-323.

Araújo, S.I.; Regazzi, A.J.; Araújo, C.V.; Cruz, C.D.; Silva, C.H.O; Viana, J.M.S. 2009. Variance component estimation with longitudinal data: a simulation study with alternative methods. Crop Breeding and Applied Biotechnology 9: 202-209.

Atkinson, L.D.; Hilton, H.W.; Pink, D.A.C. 2013a. A study of variation in the tendency for postharvest discoloration in a lettuce (Lactuca sativa) diversity set. International Journal of Food Science and Technology 48: 801-807.

Atkinson, L.D.; Mchale, L.K.; Truco, M.J.; Hilton, H.W.; Lynn, J.; Schut, J.W.; Michelmore, R.W.; Hand, P.; Pink, D.A.C. 2013b. An intra-specific linkage map of lettuce (Lactuca sativa) and genetic analysis of postharvest discolouration traits. Theoretical and Applied Genetics 126: 2737-2752.

Ayaz, F.A.; Hayirlioglu-Ayaz, S.; Alpay-Karaoglu, S.; Gruz, J.; Valentova, K.; Ulrichova, J.; Strnad, M. 2008. Phenolic acid contents of kale (Brassica oleracea L. var. acephala DC.) extracts and their antioxidant and antibacterial activities. Food Chemistry 107: 19-25.

Barnett, A.G.; Koper, N.; Dobson, A.J.; Schmiegelow, F.; Manseau, M. 2010. Using information criteria to select the correct variancecovariance structure for longitudinal data in ecology. Methods in Ecology and Evolution 1: 15-24.

Cecon, P.R.; Silva, F.F.; Ferreira, A.; Ferrão, R.G.; Carneiro, A.P.S.; Detmann, E.; Faria, P.N.; Morais, T.S. Da S. 2008. Repeated measures analysis in the evaluation of clones 'Conilon' coffee = Análise de medidas repetidas na avaliação de clones de café 'Conilon'. Pesquisa Agropecuária Brasileira 43: 1171-1176.

García, P.F.; Vallejo, G.; Livacic-Rojas, P.; Herrero, H.; Cuesta, M. 2010. Comparative robustness of six tests in repeated measures designs with specified departures from sphericity. Quality \& Quantity 44: 289-301.

Liu, Y.; Li, Z.; Xiong, H.; Gao, X.; Wu, J.; Wu, S. 2013. Understanding and enhancement of internal clustering validation measures. IEEE Transactions on Cybernetics 43: 982-993.

Lemos, M.; Santin, J.R.; Júnior, L.C.K.; Niero, R.; Andrade, S.F.D. 2011. Gastroprotective activity of hydroalcoholic extract obtained from the leaves of Brassica oleracea var. acephala DC in different animal models. Journal of Ethnopharmacology 138: 503-507.

Martínez-Sánchez, A.; Tudela, J.A.; Luna, C.; Allende, A.; Gil, M.I. 2011. Low oxygen levels and light exposure affect quality of freshcut Romaine lettuce. Postharvest Biology and Technology 59: 34-42.

Sousa, C.; Taveira, M.; Valentao, P.; Fernandes, F.; Pereira, J.A.; Estevinho, L.; Bento, A.; Ferreres, F.; Seabra, R.M.; Andrade, P.B. 2008. Inflorescences of Brassicacea species as source of bioactive compounds: a comparative study. Food Chemistry 110: 953-961.

Souza, L.A.; Carneiro, P.L.S.; Malhado, C.H.M.; Silva, F.F.; Silveira, F.G. 2013. Traditional and alternative nonlinear models for estimating the growth of Morada Nova sheep. Revista Brasileira de Zootecnia 42: 651-655. 